\title{
A LEITURA COMO FUNÇÃO TERAPÊUTICA: BIBLIOTERAPIA
}

THE READING AS A THERAPEUTICAL FUNCTION: BIBLIOTHERAPY

Clarice Fortkamp Caldin

Mestre em Literatura -UFSC, 2001

Professora do Departamento de Ciência da Informação da UFSC e-mail: claricef@matrix.com.br

\section{Resumo}

A biblioterapia clássica admite a possibilidade de terapia por meio da leitura de textos literários. Contempla a leitura de histórias e os comentários adicionais a ela. Propõe práticas de leitura que proporcionem a interpretação do texto. $O$ fundamento filosófico essencial da biblioterapia é a "identidade dinâmica". O processo de identificação do leitor/ouvinte vale-se da introjeção e da projeção. Parte-se do pressuposto que toda experiência poética é catártica e que a liberação da emoção produz uma reação de alívio da tensão e purifica a psique, com valor terapêutico.

Palavras-chave: biblioterapia; função terapêutica da leitura; catarse.

\section{INTRODUÇÃO}

A função terapêutica da leitura admite a possibilidade de a literatura proporcionar a pacificação das emoções. Remontando a Aristóteles, observa-se que o filósofo analisa a liberação da emoção resultante da tragédia - a catarse. $O$ ato de excitamento das emoções de piedade e medo proporcionaria alívio prazeroso. A leitura do texto literário, portanto, opera no leitor e no ouvinte o efeito de placidez, e a literatura possui a virtude de ser sedativa e curativa.

A relação entre psique humana e literatura não é nova. Foi, inicialmente, alicerçada pelas emblemáticas observações psicanalíticas de Freud sobre a escrita como arte poética desde os gregos até alguns de seus representantes modernos como Shakespeare e Dostoiewski. Posteriormente, recebeu uma análise de Jung, que viu em Goethe, Spitteler, Nietzche, Blake e Dante personalidades criativas e transformadoras do mundo. Enfatizada, também, pela linhagem marxista com Vygostky na psicologia infantil ou com a atividade de Sartre entre a literatura e a filosofia existencial, essa relação foi se confirmando em todo o século XX.

Ao considerar as teorias psicanalíticas do efeito literário, Wolfgang Iser, expoente da Escola de Constança que organiza os princípios da Estética da Recepção, discutiu criticamente os estudos de Norman Holland e Simon Lesser sobre as reações dos leitores. Verificou que, para ambos, a literatura tem um caráter compensatório. Muito embora Iser nutrisse algumas restrições às análises efetuadas por eles a respeito do significado dos textos literários, concluiu que "a idéia de que os textos literários mudam, em um sentido terapêutico, 
o estado psíquico do leitor que pode assim descobrir o verdadeiro significado já é algo tanto trivial" (ISER, 1999, v. 1, p. 85).

Assim, pode-se dizer que existe uma terapia por meio de livros. Tal terapia recebe o nome específico de biblioterapia, originada de dois termos gregos biblion - livro, e therapeia - tratamento.

O presente artigo tem por finalidade fornecer um referencial teórico da biblioterapia aos estudantes de biblioteconomia e bibliotecários que nutram o desejo de trabalhar com a função terapêutica da leitura. Para tanto, apresenta-se de forma didática, contemplando os conceitos e objetivos da biblioterapia, seu fundamento filosófico, o método biblioterapêutico, os componentes biblioterapêuticos e as aplicações da biblioterapia.

\section{CONCEITOS E OBJETIVOS DA BIBLIOTERAPIA}

Alice Bryan (apud SHRODES, 1949), define biblioterapia como a prescrição de materiais de leitura que auxiliem a desenvolver maturidade e nutram e mantenham a saúde mental. Inclui na biblioterapia; romances, poesias, peças, filosofia, ética, religião, arte, história e livros científicos. Apresenta como objetivos: permitir ao leitor verificar que há mais de uma solução para seu problema; auxiliar o leitor a verificar suas emoções em paralelo às emoções dos outros; ajudar o leitor a pensar na experiência vicária em termos humanos e não materiais; proporcionar informações necessárias para a solução dos problemas, e, encorajar o leitor a encarar sua situação de forma realista de forma a conduzir à ação. Sua teoria é de que os indivíduos são personalidades integradas e, portanto, a criança deve ser vista como um todo e educada emocional e intelectualmente. Vê a literatura ficcional como um meio de afetar o ajustamento total do indivíduo. Recomenda a cooperação entre bibliotecários e psicólogos, pois entende a biblioterapia como um dos serviços da biblioteca.

L.H. Tweffort (apud SHRODES, 1949), conceitua biblioterapia como sendo um método subsidiário da psicoterapia; um auxílio no tratamento que, através da leitura, busca a aquisição de um conhecimento melhor de si mesmo e das reações dos outros, resultando em um melhor ajustamento à vida. Lista como objetivos da biblioterapia: introspecção para o crescimento emocional; melhor entendimento das emoções; verbalizar e exteriorizar os problemas; ver objetivamente os problemas, afastar a sensação de isolamento; verificar falhas alheias semelhantes às suas; aferir valores; realizar movimentos criativos e estimular novos interesses. Recomenda livros de higiene mental e classifica-os de acordo com as fases da vida: infância, adolescência e idade adulta. 
Para Kenneth Appel (apud SHRODES, 1949), biblioterapia é o uso de livros, artigos e panfletos como coadjuvantes no tratamento psiquiátrico. Elenca como objetivos: adquirir informação sobre a psicologia e a físiologia do comportamento humano; capacitar o indivíduo a se conhecer melhor; criar interesse em algo exterior ao indivíduo; proporcionar a familiarização com a realidade externa; provocar a liberação dos processos inconscientes; oferecer a oportunidade de identificação e compensação; clarificar as dificuldades individuais; realizar as experiências do outro para obter a cura e auxiliar o indivíduo a viver mais efetivamente. Appel observa, como critérios para a seleção de livros, as necessidades terapêuticas e educacionais do paciente.

Segundo Louis Gottschalk (apud SHRODES, 1949), constituem objetivos da biblioterapia: auxiliar o paciente a entender melhor suas reações psicológicas e físicas de frustração e conflito; ajudar o paciente a conversar sobre seus problemas; favorecer a diminuição do conflito pelo aumento da auto-estima ao perceber que seu problema já foi vivido por outros; prestar auxílio ao paciente na análise do seu comportamento; proporcionar experiência ao leitor sem que o mesmo passe pelos perigos reais; reforçar padrões culturais e sociais aceitáveis, e, estimular a imaginação.

Louise Rosenblatt (apud SHRODES, 1949) analisa a literatura ficcional como ajuda para o ajustamento social e pessoal. Sua teoria é de que a literatura imaginativa é útil para ajustar o indivíduo tanto em relação aos seus conflitos íntimos como em conflitos com outros. Para a Autora, pensamento e sentimento estão interligados. Por isso, acredita que o processo de pensamento reflexivo estimulado pela leitura seja um prelúdio para a ação. Apresenta os perigos da leitura de escape, que age como uma droga, aumentando o desejo de fugir da realidade, pois uma falsa imagem da vida é encontrada nesse tipo de literatura. Divide os objetivos em de cura e de prevenção. Rosenblatt considera objetivos de cura: aumentar a sensibilidade social; ajudar o indivíduo a se libertar dos medos e das obsessões de culpa: proporcionar a sublimação por meio da catarse, e, levar o ser humano a um entendimento de suas reações emocionais. Como objetivos de prevenção, aponta: prevenir o crescimento de tendências neuróticas e, conduzir a uma melhor administração dos conflitos.

Caroline Shrodes, desde 1943 já desenvolvia estudos sobre a aplicação da literatura com fins terapêuticos. Em 1949, defendeu tese obtendo título de Doutora em Filosofia e Educação na Universidade de Berkeley, na Califórnia, com o trabalho Bibliotheray: $a$ theoretical and clinica-experimental study. Baseando sua tese nos autores acima citados, formulou o conceito de biblioterapia como sendo um processo dinâmico de interação entre a 
personalidade do leitor e a literatura imaginativa, que pode atrair as emoções do leitor e liberá-las para o uso consciente e produtivo. Para a Autora, a literatura ficcional é a mais indicada para garantir uma experiência emocional do leitor, efetivando a terapia de introspecção capaz de efetuar mudanças. Explorou a teoria da catarse de Aristóteles e utilizou a teoria psicanalítica de Freud dos determinantes inconscientes do comportamento para estudar a reação dos leitores à literatura ficcional. Viu a arte como um meio de proporcionar um tipo de reconciliação entre o princípio do prazer e o princípio da realidade, em que o leitor se deixa seduzir e deriva prazer, mesmo de forma inconsciente - chamado por Freud de "princípio do prazer". Defendeu, na tese, que o processo de identificação do leitor à obra de arte vale-se da introjeção - em que certos objetos são absorvidos pelo ego, e da projeção quando a dor dentro do ego é empurrada para o exterior. Sua tese configura-se como o trabalho pioneiro experimental da biblioterapia, sendo aceita como autoridade até os dias de hoje.

A Associação das Bibliotecas de Instituições e Hospitais dos Estados Unidos (MOOD; LIMPER, 1973), adotou como definições de biblioterapia: a utilização de materiais de leitura selecionados como coadjuvante terapêutico na medicina e na psiquiatria ; a orientação na solução de problemas pessoais por meio da leitura dirigida; o tratamento do mal ajustado para promover sua recuperação à sociedade.

Para Orsini (1982), a biblioterapia é uma técnica que pode ser utilizada para fins de diagnóstico, tratamento e prevenção de moléstias e de problemas pessoais. Classificou os objetivos como sendo de nível intelectual, nível social, nível emocional e nível comportamental. Assim, a biblioterapia auxilia o auto-conhecimento pela reflexão, reforça padrões sociais desejáveis, proporciona desenvolvimento emocional pelas experiências vicárias e auxilia na mudança de comportamento.

De acordo com Mattews; Lonsdale (1992), a biblioterapia constitui-se em uma terapia de leitura imaginativa, que compreende a identificação com uma personagem, a projeção (o leitor discerne a ligação da personagem com o seu caso), a introspecção (o leitor entende e educa suas emoções), e a catarse (a resposta emocional). Seus estudos basearam-se na tese de doutorado de Caroline Shrodes, que continua sendo o referencial teórico básico das pesquisas sobre biblioterapia. Distinguiram, entretanto, três tipos a terapia de leitura: a de crescimento (cujo objetivo é divertir e educar), a factual (cujo objetivo é informar e preparar o paciente para o tratamento hospitalar) e a imaginativa (cujo objetivo é explorar os sentimentos e tratar os problemas emocionais). 
Caldin (2001), baseando seus estudos na tese de Caroline Shrodes, definiu biblioterapia como leitura dirigida e discussão em grupo, que favorece a interação entre as pessoas, levando-as a expressarem seus sentimentos: os receios, as angústias e os anseios. Dessa forma, o homem não está mais solitário para resolver seus problemas; ele os partilha com seus semelhantes, em uma troca de experiências e valores. Direcionando a biblioterapia para a infância, apresentou como objetivos básicos da função terapêutica da leitura, o proporcionar uma forma de as crianças comunicarem-se, de perderem a timidez, de exporem seus problemas emocionais e quiçá físicos. Entendeu a biblioterapia como catarse, que vale-se da identificação (pela projeção e pela introjeção), da introspecção e do humor. Verificou, na recepção do texto literário para a infância, a validade de tal texto oferecer moderação das emoções às crianças.

\section{FUNDAMENTO FILOSÓFICO DA BIBLIOTERAPIA}

De acordo com Marc-Alain Ouaknin (1996, p. 97), a tese central da biblioterapia é que o ser humano, como criação contínua e em movimento constante, "encontra suas forças no processo narrativo-interpretativo da atividade da leitura".

A leitura implica uma interpretação - que é em si mesma uma terapia, posto que evoca a idéia de liberdade - pois permite a atribuição de vários sentidos ao texto. O leitor rejeita o que lhe desgosta e valoriza o que lhe apraz, dando vida e movimento às palavras, numa contestação ao caminho já traçado e numa busca de novos caminhos. A biblioterapia contempla não apenas a leitura, mas também o comentário que lhe é adicional. Assim, as palavras se seguem umas às outras - texto escrito e oralidade, o dito e o desdito, a afirmação e a negação, o fazer e o desfazer, o ler e o falar - em uma imbricação que conduz à reflexão, ao encontro das múltiplas verdades, em que o curar se configura como o abrir-se a uma outra dimensão.

Para Ouaknin (1996, p. 198), "a biblioterapia é primariamente uma filosofia existencial e uma filosofia do livro", que sublinha que o homem é um "ser dotado de uma relação com o livro". Dessa forma, essa relação com o livro - a leitura - permite ao homem compreender o texto e se compreender. O leitor, ao interpretar, passa a fazer parte do texto interpretado. A interpretação é a junção da explicação objetiva do texto e da sua compreensão subjetiva. A interpretação descobre um outro mundo, o mundo do texto, com "as variações imaginativas que a literatura opera sobre o real" (OUAKNIN, 1996, p. 200). A biblioterapia, portanto, propõe práticas de leitura que proporcionem a interpretação dos textos. 
O fundamento filosófico essencial da biblioterapia é "a identidade em movimento" ou a "identidade dinâmica". Segundo Ouaknin (1996, p. 98, 99), "para a biblioterapia, a identidade é um não lugar", pois o "ser humano é um 'ser de caminho, um homem em marcha". Assim, ao lado da identidade estável, as marcas distintivas do homem - caráter, nome, profissão, posição social - existe a identidade construída pelas identificações adquiridas nos modelos, heróis ou valores nos quais a pessoa se reconhece, que poderia ser chamada de identidade dinâmica. As histórias, contadas ou lidas, propõem ao ouvinte ou leitor a possibilidade de "mudança de direção da trajetória inicial de sua história" (OUAKNIN, 1996, p. 106). Dessa forma, as personagens, situações ou intrigas que aparecem nas histórias ficcionais permitem ao ouvinte ou leitor identificações literárias construídas a partir da identidade narrativa que circula entre o texto e a ação.

\section{O MÉTODO BIBLIOTERAPÊUTICO}

O método biblioterapêutico consiste em uma dinamização e ativação existencial por meio da dinamização e ativação da linguagem. As palavras não são neutras. A linguagem metafórica conduz o homem para além de si mesmo; ele se torna outro, livre no pensamento e na ação.

A linguagem em movimento, o diálogo, é o fundamento da biblioterapia. O plurarismo interpretativo dos comentários aos textos deixa claro que cada um pode manifestar sua verdade e ter sua visão do mundo. Entre os parceiros do diálogo há o texto, que funciona como objeto intermediário. No diálogo biblioterapêutico é o texto que abre espaço para os comentários e interpretações que propõem uma escolha de pensamento e de comportamento. Assim, as diversas interpretações permitem a existência da alteridade e a criação de novos sentidos. A biblioterapia não se confunde com a psicoterapia, posto que esta última é o encontro entre paciente e terapeuta e a primeira se configura como o encontro entre ouvinte e leitor em que o texto desempenha o papel de terapeuta. Além da leitura, os comentários, os gestos, os sorrisos, os encontros são também terapêuticos à medida que fornecessem a garantia de que não estamos sozinhos. O texto une o grupo.

\section{COMPONENTES BIBLIOTERAPÊUTICOS}

\subsection{A catarse}

Ao enfocar a leitura como função terapêutica, defende-se a idéia de terapia por meio de textos literários. Muito embora a palavra terapia, em termos restritivos, possua um sentido 
curativo, na realidade envolve muito mais do que a cura - implica em uma atitude preventiva. Assim é que o sentido primário da palavra terapeuta é aquele que cuida, consistindo os primeiros terapeutas em médicos e filósofos -os que cuidam do corpo e do espírito.

É certo que as palavras são o instrumento essencial do tratamento do espírito. Convencem, emocionam, influenciam - e pode-se inferir aqui o sentido da catarse aristotélica.

Generalizando o efeito catártico, é possível substituir o teatro pelos textos literários, visto que os mesmos também provocam emoções e paixões. Cumpre lembrar que Aristóteles concebeu o espetáculo trágico como capaz de transformar o medo e a piedade em prazer estético e isto porque tais emoções são despertadas por uma representação artística, já tendo perdido, assim, sua força nociva (ARISTÓTELES, 1966). Processa-se da mesma forma a catarse por meio dos textos literários - uma "alegria serena" de que fala Aristóteles (1996) advém da leitura de narrativas que transformam em fruição a piedade e o temor. Partindo do pressuposto que toda experiência poética é catártica, vale lembrar que o filósofo tomou de empréstimo o vocábulo médico que indica purificação do corpo de elementos nocivos e utilizou-o no sentido de purificação psicológica e intelectual. Ao assim fazer, estendeu o alcance do termo para incorporá-lo também ao fenômeno estético. Dessa forma, catarse pode ser entendida como pacificação, serenidade e alívio das emoções. É nessa perspectiva que se enfoca a leitura de textos literários como desempenhando uma função catártica. Não está, portanto, em desacordo com a moderna concepção de catarse, em que o termo é utilizado com referência à função libertadora da arte.

\subsection{0 humor}

Textos que privilegiem o humor constituem um exemplo de possibilidade terapêutica por meio da leitura. Ao buscar em Freud apoio teórico para a compreensão do humor, observa-se que o humor se configura como um triunfo do narcisismo, posto quer o ego se recusa a sofrer. O humor é, pois, a rebelião do ego contra as circunstâncias adversas, transformando o que poderia ser objeto de dor em objeto de prazer. É a ação do superego agindo sobre o ego a fim de protegê-lo contra a dor. (FREUD, 1969).

\subsection{A identificação}

A identificação - fator importante na teoria freudiana do desenvolvimento da personalidade - começa cedo na nossa vida. As crianças se identificam com os pais, com pessoas que admiram e com os animais. Segundo o Vocabulário de Psicanálise 
(LAPLANCHE; PONTALIS, 1994, p. 226), a identificação é "um processo psicológico pelo qual um sujeito assimila um aspecto, uma propriedade, um atributo do outro e se transforma, total ou parcialmente, segundo o modelo desse outro".

\section{$5.4 \mathrm{~A}$ introjeção}

A introjeção constitui-se em um processo evidenciado pela investigação analítica: "o sujeito faz passar, de um modo fantasístico, de 'fora' para dentro', objetos e qualidades inerentes a esses objetos" (LAPLANCHE; PONTALIS, 1994, p. 248). Está estreitamente relacionada com a identificação.

\subsection{A projeção}

A projeção é a transferência aos outros de nossas idéias, sentimentos, intenções, expectativas e desejos. Segundo Laplanche; Pontalis (1994, p. 374), a projeção é, "no sentido propriamente dito, operação pela qual o sujeito expulsa de si e localiza no outro - pessoa ou coisa - qualidades, sentimentos, desejos e mesmo 'objetos' que lê, desconhece, ou recusa nele.

\subsection{A introspecção}

A introspeção, segundo Michaelis (1998, p. 699), é a "descrição da experiência pessoal em termos de elementos e atitudes" a "observação, por uma determinada pessoa, de seus próprios processos mentais". Dessa forma, a leitura, ao favorecer a introspecção, leva o indivíduo a refletir sobre os seus sentimentos - o que é terapêutico, pois sempre desponta a possibilidade de mudança comportamental..

\section{APLICAÇÕES DA BIBLIOTERAPIA}

A biblioterapia tem sido utilizada em hospitais, prisões, asilos, e no tratamento de problemas psicológicos em crianças, jovens, adultos, deficientes físicos, doentes crônicos e viciados.

Shrodes (1949) realizou, com sua investigação, um detalhamento da aplicação da biblioterapia, mencionando alguns autores, que serão listados a seguir. Moore fez uma abordagem da biblioterapia como tratamento de delinquentes juvenis, apresentando seus estudos nesse campo com resultados positivos. Menninger descreveu os propósitos do Programa de Biblioterapia na Clínica Menninger: oportunizar recreação e interação social; 
encorajar o indivíduo a criar interesse externo e assisti-lo na obtenção de contato com a realidade externa; propiciar a introspecção dos problemas e conduzir a uma gratificação narcisística com o fortalecimento do ego. Como bases para a prescrição de livros são avaliadas a necessidade terapêutica presente, a base do indivíduo e a apresentação sintomática. Schenek, que também atuou na Clínica Menninger, utilizou a biblioterapia como auxílio psicológico no tratamento hipoglicêmico da esquizofrenia e no tratamento da depressão. Trabalhando com pacientes dementes, Quint usou a leitura nos seus momentos de lucidez, como método de trazê-los de volta à realidade. A utilização da biblioterapia nas escolas é defendida por Kircher, que acredita no alívio psicológico através do vivenciar as emoções do herói como um meio de liberar as emoções do leitor, mesmo que a leitura não produza uma reação imediata e sim, atrasada. Auerbach indicou a leitura como higiene mental e sua teoria é que a biblioterapia não funciona com indivíduos severamente neuróticos ou perturbados emocionalmente.

Caroline Shrodes (1949), como metodologia para o estudo clínico-experimental da biblioterapia, utilizou o estudo de casos individuais, sob uma base holística de psicologia dinâmica. A seleção incidiu sobre um grupo de cinqüenta estudantes inscritos em um Curso de Comunicação Básica. Escolheu cinco estudantes como amostra da pesquisa, um dos quais recebeu atenção especial, pelas suas reações-respostas à biblioterapia. Seu estudo explorou a teoria e a prática da biblioterapia em jovens e adultos saudáveis.

Mildred T. Mood, presidenta do Comitê sobre Biblioteapia e Hilda K. Limper, presidenta do Sub-Comitê sobre a Criança em Dificuldade, motivadas pelo workshop interdisciplinar sobre biblioterapia realizado em 1964 em Saint-Louis, publicaram o livro Bibliotherapy: methods and mateirals (1973), patrocinado pela Association of Hospital and Institution Libraries. Na Parte I, o Comitê de Biblioterapia examinou os aspectos da terapia da leitura às pessoas hospitalizadas com problemas diversos e, na Parte II, o Sub-comitê sobre a Criança em Dificuldade escolheu as áreas com problemas evidentes e selecionou títulos específicos que poderiam ser úteis para os orientadores de crianças e jovens com dificuldade de adaptação.

Maurice Barker (1979), psicólogo clínico do Hôpital Sainte-Justine em Montréal, por meio de conferências na Université de Montréal, na Université McGill, no Congrès de l'ASTED e de um artigo publicado na Revista Documentation et Bibliothèques, na década de setenta, mostrou preocupação com a leitura para jovens. No artigo Bibliothèques et lectures pour jeunes, apresentou uma proposta para a biblioterapia de adolescentes. Lamentou o fato 
de os autores não se preocuparem muito com essa faixa etária, o que dificulta o uso do livro com finalidade terapêutica para esse público.

Alves (1982) discutiu o papel da biblioterapia nas prisões. Considerou necessário à reeducação do presidiário, o direito à leitura como fonte de informação e como fator de diminuição do stress advindo da situação de perda de liberdade. Aliou à terapia convencional - o trabalho e o lazer - a biblioterapia, que deveria ser realizada por um bibliotecário em parceria com o psicólogo e o assistente social do presídio.

O estudo de Fernández Vasquez (1989), ao executar um trabalho de biblioterapia para idosos no Lar da Previdência Carneiro da Cunha, em João Pessoa, relatou os resultados obtidos pela leitura de textos ficcionais em sessões de leitura em grupo e sessões de leitura individual. Objetivou informar sobre a importância da atividade biblioterapêutica a uma clientela específica: os idosos. Através de um programa de leituras dirigidas, procurou despertar o gosto pela leitura e melhorar o quadro psíquico e mental da clientela. Propôs, adicionalmente, a implantação de um programa permanente de biblioterapia aos residentes no asilo, pois constatou uma diminuição dos quadros de ansiedade e depressão da população estudada, após as sessões de leitura dirigida.

O Fundo de Pesquisa da Bibliografia Nacional Britânica patrocinou, em 1990, um projeto de pesquisa sobre a terapia da leitura com crianças no hospital. O relatório da pesquisa, apresentado no ano seguinte, apontou, por meio de questionários, entrevistas estruturadas e debates com os membros da equipe em hospitais de diferentes partes da Inglaterra e Wales, que 73\% utilizavam livros, fitas, vídeos e gravuras para fins terapêuticos em crianças, como meio de comunicação e preparação para o tratamento e para lidar com sentimentos tais como raiva e frustração. O relatório incluiu também dados de pesquisas sobre o assunto, a maioria realizada nos Estados Unidos, Reino Unido e Alemanha. Constatou-se a existência de considerável literatura sobre a terapia de leitura em crianças autistas, com medo do escuro, situação de morte e luto, filhos de pais divorciados e alcoólatras, além de doentes mentais (MATTEWS; LONSDALE, 1992).

Têm-se, também na Paraíba, o estudo de Pereira (1996), que desenvolveu um trabalho pioneiro no Brasil, com a biblioterapia para deficientes visuais em João Pessoa. Preocupada com a preparação educacional e a especialização profissional do deficiente visual que auxiliariam sua integração na sociedade, propôs a implantação de um programa de biblioterapia para portadores de deficiência visual em bibliotecas públicas. 
Seitz (2000), priorizou a biblioterapia com pacientes internados na Clínica Médica do Hospital Universitário da Universidade Federal de Santa Catarina. Verificou que a prática biblioterapêutica foi útil no processo de hospitalização, como fonte de lazer e de informação, na interação entre bibliotecário/paciente/enfermeiros e no processo de socialização dos pacientes. Enfocou a biblioterapia como lazer e humanização do hospital e do tratamento das doenças..

Caldin (2001) analisou o projeto Literatura infantil e Medicina pediátrica: uma aproximação de integração humana, desenvolvido pela Pontifícia Universidade Católica do Rio Grande do Sul e cinco sub-projetos vinculados ao projeto-matriz Por uma Política de Incentivo à Leitura, da Universidade da Região de Joinville. Tais projetos, desenvolvidos por formandos e coordenados por professoras do Curso de Letras das referidas universidades, desenvolveram trabalho de terapia por meio da leitura na ala pediátrica de hospitais de Porto Alegre e de Joinville. Constatou que as histórias lidas às crianças amenizaram sua situação incapacitante e proporcionaram alívio temporário das dores e dos medos advindos da doença e do ambiente hospitalar. O resgate do sonho, do imaginário e do lúdico forneceu um suporte emocional às crianças enfermas. Os registros dos leitores de histórias corroboraram a eficácia da biblioterapia em explorar a literatura infantil como integradora no processo de cura que envolve mente e corpo.

\section{CONSIDERAÇÕES FINAIS}

A biblioterapia constitui-se em uma atividade interdisciplinar, podendo ser desenvolvida em parceria com a Biblioteconomia, a Literatura, a Educação, a Medicina, a Psicologia e a Enfermagem. Tal interdisciplinaridade confere-lhe um lugar de destaque no cenário dos estudos culturais. É um lugar estratégico que permite buscar aliados em vários campos e um exercício aberto a críticas, contribuições e parceiras.

A terapia ocorre pelo próprio texto, sujeito a interpretações diferentes por pessoas diferentes. Tanto é o texto que "cura", que já foi sugerido, inclusive, o uso do termo literapia, unindo literatura e terapia, com ênfase no literário e no ficcional. Permanece, entretanto, o uso do termo tradicional, biblioterapia.

Vale destacar que não é a designação o mais importante na atividade de terapia da leitura, mas, o resultado obtido. 


\begin{abstract}
The classic bibliotherapy admits the possibility of therapy by means of reading of literary texts. It contemplates the reading of stories and commentaries about them. It considers the practical $f$ reading that provides text interpretation. The philosophical essential of bibliotherapy is their "dynamic identity". The process of identification of the reader and or listening, uses the introjection and the projection. It estimates that all poetical experience is cathartic and that the clearing of emotions produces a reaction of relief of tensions, purifying the psique, with therapeutical value.
\end{abstract}

Key word: bibliotherapy; therapeutical function of reading; catharsis

\title{
FONTES BIBLIOGRÁFICAS
}

ALVES, Maria Helena Hess. A aplicação da biblioterapia no processo de reintegração social.

R. bras. Biblioteconon. e Doc., v. 15, n.1/2 p. 54-61, jan./jun. 1982.

ARISTÓTELES. Poética. Tradução de Eudoro de Souza. Porto Alegre: Globo, 1966.

BARKER, Maurice. Bibliothèques et lectures pour jeunes: propos sur la bibliothérapie.

Documentation et bibliothèques, v. 25, n. 41, p. 213-215, déc. 1979.

CALDIN, Clarice Forkamp. A poética da voz e da letra na literatura infantil: (leitura de alguns projetos de contar e ler para crianças). 2001. 261 f. Dissertação (Mestrado em Literatura) - Universidade Federal de Santa Catarina, Florianópolis.

FERNÁNDEZ VÁZQUES, Maria do Socorro Azevedo Félix. Biblioterapia para idosos: um estudo de caso no Lar da Providência Carneiro da Cunha. 1989. 140 f. Dissertação (Mestrado em Biblioteconomia) - Universidade Federal da Paraíba, João Pessoa.

FREUD, Sigmund. Os chistes e suas relações com o inconsciente. Tradução de Margarida Salomão. Rio de Janeiro: Imago, 1969.

Obras completas. Tradução de Odilon Gallotti et al. Rio de Janeiro: Delta, [197-]. V.6.

ISER, Wolfgang. O ato da leitura: uma teoria do efeito estético. Tradução de Johannes Kretschemer. São Paulo: Ed. 34, 1999. 2 v.

LAPLANCHE, Jean; PONTALIS, J.B. Vocabulário de psicanálise. Tradução de Pedro Tamen. São Paulo: M. Fontes, 1994.

MATTEWS, David; LONSDALE, Ray. Children in hospital: II. Reading therapy and children in hospital. Health Libraries Review, v. 9, n. 1, p. 14-26, 1992.

MICHAELIS: pequeno dicionário da língua portuguesa. São Paulo: Melhoramentos, 1998.

MOOD, Mildred; LIMPER, Hilda K. Bibliotherapy: methods and materials. Chicago:

American Library Association, 1971.

ORSINI, Maria Stella. O uso da literatura para fins terapêuticos: biblioterapia. Comunicações e Artes, n. 11, p. 139-149, 1982.

OUAKNIN, Marc-Alain. Biblioterapia. Tradução de Nicolás Niymi Campanário. São Paulo: Loyola, 1996.

PEREIRA, Marília Mesquita Guedes. Biblioterapia: proposta de um programa de leitura para portadores de deficiência visual em bibliotecas públicas. João Pessoa: Ed. Universitária, 1996.

SARTRE, Jean-Paul. Que é literatura? Tradução de Carlos Felipe Moisés. São Paulo: Ática, [19--].

Enc. Bibli: R. Eletr. Bibliotecon. Ci. Inf., ISSN 1518-2924, Florianópolis, Brasil, n.12, p. 32-44, 2001. 
SEITZ, Eva Maria. Biblioterapia: uma experiência com pacientes internados em clínica médica. 2000. 79 f. Dissertação (Mestrado em Engenharia de Produção)- Universidade Federal de Santa Catarina, Florianópolis.

SHRODES, Caroline. Bibliotherapy: a theoretical and clinical-experimental study. 1949. 344 f. Dissertation (Doctor of Philosophy in Education) - University of California, Berkeley. SOUZA, Solange Jobim e. Infância e linguagem: Bakhtin, Vygotsky e Benjamin. [s.1.]: Papirus, [1995?].

VARIN, Louise; AUBIN, Robert. Les livres qui font du bien. Documentation et bibliothèques, v. 41, n.2, p. 95-100, avr./juin 1995. 